\title{
Rescue antegrade diathermic dilation of hyperplastic tissue at partially covered metallic stent after EUS-guided hepaticogastrostomy
}

Endoscopic ultrasonography-guided antegrade stenting (EUS-AGS) and EUSguided hepaticogastrostomy (EUS-HGS) are suitable for obstructive jaundice associated with gastric outlet obstruction or surgically altered anatomy [1]. Recently, a long partially covered self-expandable metallic stent (LPC-SEMS) has been developed to prevent stent migration and bile leakage and allow safe and effective EUS-HGS. However, one disadvantage of the LPC-SEMS is tissue hyperplasia at the uncovered portion of the stent [2]. Here, we present the case of a patient who underwent a rescue procedure using antegrade diathermic dilation for hyperplastic tissue occlusion of an LPC-SEMS and for tumor ingrowth into an uncovered SEMS placed for EUS-AGS.

A 60-year-old man with unresectable gastric cancer was admitted with gastric outlet obstruction and obstructive jaundice. He had undergone EUS-AGS using an uncovered metallic stent and EUSHCS using a LPC-SEMS (diameter $6 \mathrm{~mm}$, length $120 \mathrm{~mm}$, uncovered proximal portion $10 \mathrm{~mm}$; Taewoong Medical, Seoul, Korea). He again developed obstructive jaundice 7 months later. Antegrade cholangiography via the LPC-SEMS revealed perihilar bile duct stricture due to hyperplasia at the LPC-SEMS (> Fig. 1). It was not possible to pass a tapered endoscopic retrograde cholangiopancreatography (ERCP) catheter through the stricture ( Video 1 ). We successfully dilated the stricture using 6-Fr wire-guided diathermic dilation (Cysto-Gastro-Set; Endo-Flex, Voerde, Germany) ( Fig.2, - Video 1). Antegrade cholangiography showed free drainage through the previously hyperplastic area at the uncovered portion of the stent. No stent was placed as the previously occluded LPCSEMS was now patent ( $\mathbf{F i g . 3}$ ). Subsequent antegrade cholangiography revealed occlusion of the uncovered metallic stent due to tumor ingrowth



( Fig.4a). Passage was successfully obtained with antegrade diathermic dilation ( Fig.4b). Finally, an ultraslim uncovered SEMS (BileRush Selective, 5.7-Fr, diameter $10 \mathrm{~mm}$; Piolax Medical Devices, Kanagawa, Japan) was placed using a stent-in-stent method, without complications ( $>$ Fig. 5, > Video 1 ).

Recurrent biliary obstruction caused by tissue hyperplasia is an unresolved major problem of the LPC-SEMS, and the optimal rescue technique has not been established. EUS-guided antegrade diathermic dilation has been recently reported [3-5]. To our knowledge, this is the first report of rescue for hyperplastic tissue occlusion of an LPC-SEMS that used wire-guided antegrade diathermic dilation with no need for secondary stenting. This rescue technique is a useful method of recanalization of an LPCSEMS occluded by hyperplastic tissue.

Endoscopy_UCTN_Code_CPL_1AK_2AC

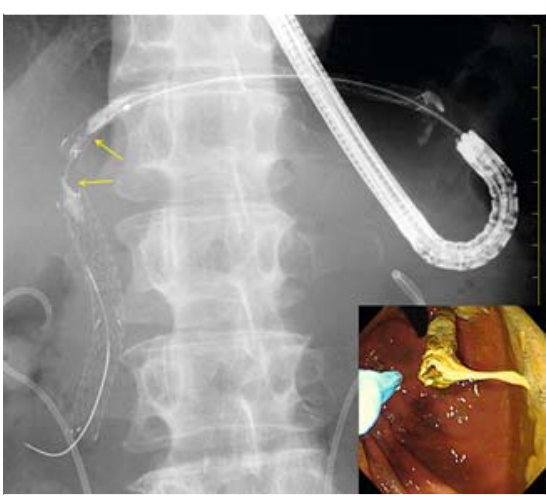

- Fig. 1 Radiographic image from a 60 -year-old man, showing perihilar bile duct stricture due to hyperplasia (arrows) at the long partially covered self-expandable metallic stent (LPC-SEMS), after endoscopic ultrasonography-guided hepaticogastrostomy 7 months earlier (inset: endoscopic image). 

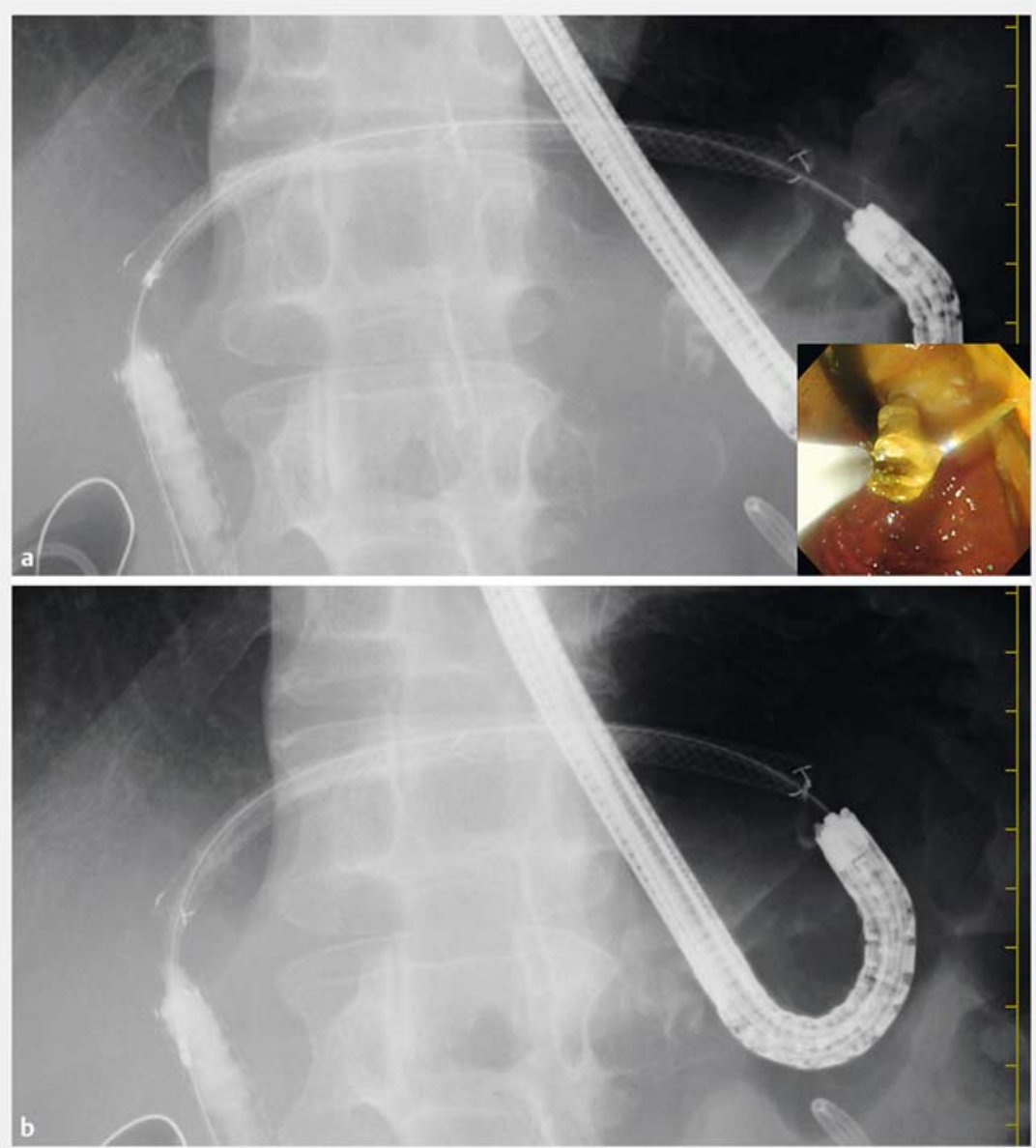

- Fig. 2 Radiographic image showing wire-guided antegrade diathermic dilation for hyperplastic tissue at the LPC-SEMS. a Before diathermic dilation; inset: endoscopic image. b After diathermic dilation.
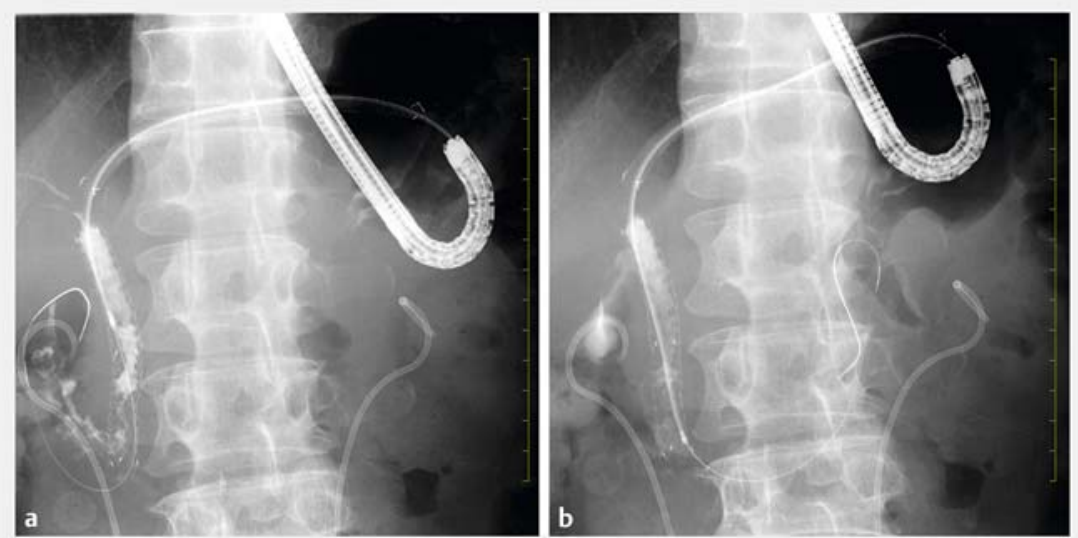

Fig.4 Radiographic images: a Tumor ingrowth in the uncovered self-expandable metallic stent in the distal bile duct, placed at endoscopic ultrasonography-guided antegrade procedure 7 months earlier. b Wire-guided antegrade diathermic dilation for the tumor ingrowth.

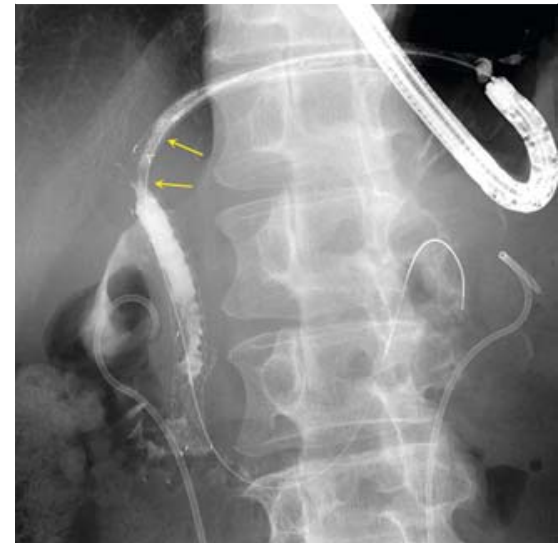

- Fig. 3 Radiographic image showing free drainage through the previously hyperplastic area (arrows) at the uncovered portion of the LPC-SEMS after wire-guided antegrade diathermic dilation.

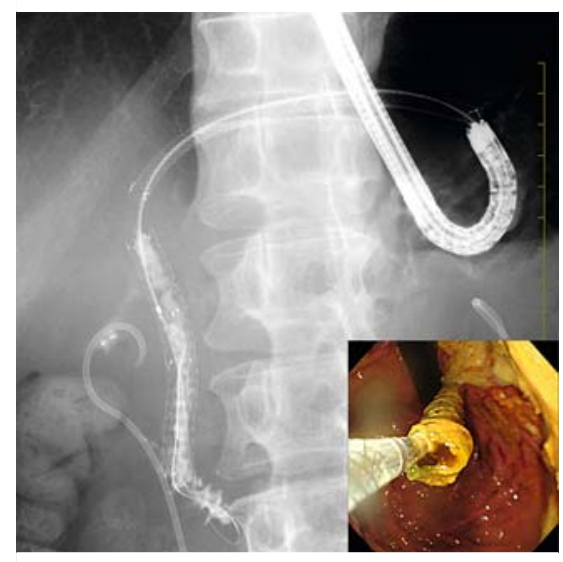

- Fig. 5 Radiographic image showing antegrade placement of ultraslim uncovered self-expandable metallic stent using the stent-in-stent method (inset: endoscopic image).

\section{Competing interests}

Dr. Kawakami is a consultant to and gives lectures for Piolax Medical Devices, Kanagawa, Japan. The other authors declare no conflict of interests for this article.

The Authors

Hiroshi Kawakami ${ }^{1,2}$, Yoshimasa Kubota ${ }^{1,2}$, Tesshin Ban ${ }^{1,2}$

1 Department of Gastroenterology and Hepatology, Faculty of Medicine, University of Miyazaki, Miyazaki, Japan

2 Center for Digestive Disease, University of Miyazaki Hospital, Miyazaki, Japan 


\section{Hiroshi Kawakami, MD, PhD}

Department of Gastroenterology and

Hepatology, Faculty of Medicine, University

of Miyazaki, 5200 Kihara, Kiyotake, Miyazaki,

Miyazaki 889-1692, Japan

Fax: +81-985-859802

hiropon@med.miyazaki-u.ac.jp

\section{References}

[1] Kawakami H, Kubota Y. Endoscopic ultrasonography-guided antegrade stenting combined with hepaticogastrostomy/hepaticojejunostomy using ultraslim instruments. Endoscopy 2017; 49: E88-E89

[2] Nakai $\mathrm{Y}$, Isayama $\mathrm{H}$, Yamamoto $\mathrm{N}$ et al. Safety and effectiveness of a long, partially covered metal stent for endoscopic ultrasound-guided hepaticogastrostomy in patients with malignant biliary obstruction. Endoscopy 2016; 48: 1125-1128
[3] Kawakami H, Kuwatani M, Sakamoto N. Endoscopic ultrasound-guided antegrade diathermic dilation followed by self-expandable metallic stent placement for anastomotic stricture after hepaticojejunostomy (with video). Dig Endosc 2014; 26: 121 - 122

[4] Kawakami H, Kuwatani M, Kawakubo K et al. Endoscopic ultrasound-guided antegrade diathermic dilation followed by self-expandable metal stent placement for malignant distal biliary stricture. Endoscopy 2014: UCTN: 46 (Suppl. 01): E328-E329

[5] Kawakami H, Kuwatani M, Kawakubo K et al. Endoscopic ultrasonography-guided antegrade diathermic dilation for the treatment of complete obstruction of a pancreaticogastrostomy. Endoscopy 2014: UCTN: 46 (Suppl. 01): E517-E518

\section{Bibliography}

DOI https://doi.org/10.1055/s-0043-117941

Published online: 13.9.2017

Endoscopy 2017; 49: E285-E287

(c) Georg Thieme Verlag KG

Stuttgart · New York

ISSN 0013-726X
ENDOSCOPY E-VIDEOS

https://eref.thieme.de/e-videos

口回 Endoscopy E-Videos is a free access online section, reporting 田: on interesting cases and new techniques in gastroenterological endoscopy. All papers include a high quality video and all contributions are freely accessible online.

This section has its own submission website at https://mc.manuscriptcentral.com/e-videos 